\title{
The Effects of Perceived Parenting and Family Functioning on Adult At- tachment: A Sample of Japanese University Students
}

\author{
Qingbo Liu ${ }^{*}$, , Masahiro Shono ${ }^{2}$ and Toshinori Kitamura*,1 \\ ${ }^{I}$ Department of Clinical Behavioral Sciences, Kumamoto University Graduate School of Medical Science, Kumamoto, \\ Japan \\ ${ }^{2}$ Yuge Hospital, Yuge, Japan
}

\begin{abstract}
Parenting styles and family functioning have been proved individually to make an important contribution to the development of adult attachment styles. However, few studies have attempted to clarify how these two factors influence adult attachment styles when taken into account simultaneously. In order to examine the relationship between adult attachment, perceived parenting, and family functioning, data derived from 1,141 males (29.6\%) and 2,709 females (70.4\%) were analyzed in the present study. The results indicated that perceived parenting predicted adult attachment and family functioning, while family functioning failed to significantly predict adult attachment. The present study also highlighted the fact that paternal and maternal parenting played equally important roles in shaping adult attachment styles of offspring.
\end{abstract}

Keywords: Adult attachment, parenting, family functioning.

\section{INTRODUCTION}

Attachment theory, based on studies of children and their primary caregivers, was proposed by Bowlby $(1969,1973$, 1980) to account for infants' social and emotional development and adjustment. Bowlby also theorized that the infant's attachment experiences are consolidated into an "internal working model" of the self, other, and self-in-relation-toother, and that this model is used by the individual to develop relationships with others throughout his or her lifespan. However, the attachment between children and their caregivers remained the principal focus of attachment theory for many years. By the late 1980s, Hazan and Shaver (1987, $1990,1994)$ had begun to apply attachment theory to the study of adults. A three forced-choice measurement of adult attachment modeled on Ainsworth's infant attachment typology was devised (e.g., secure, anxious/ambivalent, and avoidant; Ainsworth, Blehar, Waters, \& Wall, 1978). In an important consequent development, Bartholomew and Horowitz (1991) conceptualized a four-category classification of adult attachment styles in terms of the combination of working models (positive $v s$ negative) of self and others. A person with a positive model of self feels he or she is worthy of love and support. A person with a positive model of others feels people are accessible, trustworthy, and caring. Conversely, an individual possessing a negative self model feels unworthy and unlovable, and a person with a negative model of others perceives others as unavailable, unreliable, and rejecting. Based on the working models of self and others, adult attachment styles were cataloged into secure attachment and insecure attachment (Fearful, Preoccupied, and Dismissing). Individuals classified as secure have positive

*Address correspondence to either author at the Department of Clinical Behavioral Sciences (Psychological Medicine), Kumamoto University, Graduate School of Medical Sciences, 1-1-1 Honjo, Kumamoto, Japan 8608556; Tel: +81-96-373-5183; Fax: +81-96-373-5181;

E-mail: kitamura@kumamoto-u.ac.jp or drliuqb@hotmail.com models of self and others; preoccupied individuals have a negative model of self and a positive model of others; dismissing individuals have a positive model of self and a negative model of others; and in fearful individuals, models of self and others are both generally negative (Bartholomew \& Horowitz, 1991).

Parents play an important role in their children's growth from birth to adulthood. Numerous studies have examined the impact of parenting (the process of raising and educating the child) on children' development (Arendell, 1997; Aunola \& Nurmi, 2005; Baumrind, 1996; Damon, 1988; Smith, 1988). In the area of infant attachment, empirical studies have confirmed that three patterns of attachment develop partially in response to the consistency and quality of affection and support that parents give to their children, and that different parental behaviors correspond to different attachment patterns in offspring (Ainsworth et al., 1978). For example, parents who are affectionate, supportive, and sensitive to their children's needs tend to have securely attached children. Parents who consistently reject their children's demand for affection and support and encourage emotional independence too early tend to have avoidantly attached children. Finally, parents who behave inconsistently or unpredictably and use withdrawal of love as punishment tend to have anxiously attached children (Bowlby, 1973; Crittenden \& Ainsworth, 1989; Egeland \& Farber, 1984; Kochanska, Kuczynski, \& Radke-Yarrow, 1989). Similar reciprocity between parenting and attachment styles has also been found in adults. Thus, securely attached adults describe their parents as sensitive, responsive, caring, and confident, whereas insecurely attached adults describe their parents as rejecting, demanding, unconcerned, and punitive (Hazan \& Shaver, 1987; Mikulincer \& Florian, 1998).

Olson and DeFrain (2000) proposed the theoretical integration between parenting styles and family functioning. They have noted that balanced family types are positively related to authoritative parenting and negatively related to 
authoritarian parenting. Furthermore, this frame of reference was addressed by theory-driven studies (McFarlane, Bellissimo, \& Norman, 1995; Mupinga, Garrison, \& Pierce, 2002). Two widely accepted and important dimensions of family functioning are family adaptability and cohesion. In Olson's circumplex model of family systems (Olson, 1991), cohesion relates to the reciprocal emotional bonding among family members, whereas adaptability is described as the ability of a marital or family system to change its power structure, role relationships, and relationship rules in response to situational and developmental stress. A balanced level of both cohesion and adaptability is the most beneficial to marital and family development. Therefore, family functioning may be regarded as another factor that has an important influence on a person's attachment style (Mikulincer \& Florian, 1999). The study of Mikulincer and Florian has indicated that high levels of family expressiveness and low levels of family conflict are positively associated with a secure attachment style in offspring; low levels of family adaptability, cohesion, and expressiveness are related to avoidant attachment in offspring; and high levels of familial conflict are related to anxious-ambivalent attachment in offspring.

To date, although the considerable number of studies mentioned above have demonstrated that parenting styles and family functioning make an important contribution to the development of adult attachment styles, few studies have tried to elucidate how these two factors influence adult attachment style if they are taken into account simultaneously. Therefore, a questionnaire including assessments of perceived parenting, family functioning, and adult attachment was used in the present study in order to examine the specific impact that parenting and family functioning have on adult attachment.

It was hypothesized (a) that adult attachment style would be predicted by perceived early parenting and current family functioning when these two factors are taken into account simultaneously, and (b) that current family functioning would be predicted by perceived early parenting.

\section{SAMPLE AND METHODOLOGY}

\section{Sample and Procedure}

With the consent of each president of 110 universities in Japan, a total of 33,779 questionnaires were sent to each university. In order to avoid selection bias as much as possible, the questionnaires were required to be distributed to all the students in a given setting, such as in class, in students' sections, at annual medical check-ups or at campus festivals. The survey was completely anonymous. Answered questionnaires were returned by mail directly from each respondent using a cash on delivery envelope. A total of 4,357 questionnaires were collected. Because it was impractical to supervise all distribution processes in 110 universities, the exact response rate was unknown.

Before the beginning of the investigation, the present study was approved by the Ethical Committee of the National Institute of Mental Health, National Center of Neurology and Psychiatry, Kohnodai, Japan.

The respondents included 1,392 men (mean age and SD of 20.4 and 2.0) and 2,965 women (mean age and SD of 20.3 and 1.8). Of these, 28 were married. A total of 2,055 (47.2\%) reported that they were currently living with their family; $1,789(41.1 \%)$ were living alone; $358(8.2 \%)$ were living in a group accommodation; $73(1.7 \%)$ were living with a roommate or relatives; and $67(1.5 \%)$ had other accommodation conditions (14 did not report on this matter). Because the aim of the present study was to examine the relationship among parental rearing, original family functioning, and adult attachment, the married participants were not regarded as eligible. Therefore, excluding 479 missing data and 28 married participants, we analyzed a final sample of 1,141 males $(29.6 \%)$ and 2,709 females $(70.4 \%)$. The mean (SD) age of the sample was $20.2(\mathrm{SD}=1.5)$ years.

\section{Questionnaires}

Adult Attachment. The Relationship Questionnaire (RQ; Bartholomew \& Horowitz, 1991) consists of four short paragraphs describing the four styles (Secure, Fearful, Preoccupied, and Dismissing) of adult attachment. Each participant was required to rate on a 7-point scale from 1 (does not apply to me at all) to 7 (applies to me very much) the extent to which each description would correspond to his or her relationship with his or her partner and close adult peers. The validation of the RQ was reported based on multiple measures of attachment including interview measures (Bartholomew \& Horowiz, 1991; Griffin \& Batholomew, 1994). Matsuoka et al. (2006) reported the psychometric properties of the Japanese version of the RQ and the singlefactor structure was proposed by an exploratory factor analysis with Promax rotation. Therefore, Total Attachment Score (TAS) was calculated by subtracting the Fearful, Preoccupied and Dismissing scores from the Secure score, with a higher TAS indicating more secure adult attachment (Matsuoka et al., 2006).

Family Functioning. The Family Adaptability and Cohesion Evaluation Scale (FACES-III; Olson, Portner, \& Lavee, 1985) is a self-report 20-item measurement with a 5point scale to measure the functioning -- Adaptability and Cohesion -- of the current family. The FACES-III has been reported as reliable and valid (Grotevant \& Carlson, 1989). Hasui, Kishida, and Kitamura (2004) have reported the twofactor structure of Japanese version of FACES-III that fits the Japanese population.

Perceived Parenting. The Parental Bonding Instrument (PBI; Parker, Tupling, \& Brown, 1979) is a 25 -item selfrating measure in which the respondents recall the attitudes and behaviors of their parents during the first 16 years of life. In Parker's original two-factor structure, there are 12 items for the Care dimension and 13 items for the Overprotection dimension. Each respondent was asked to rate each item on a 1 to 4 point scale ranging from very unlikely to very likely. A Japanese version of the PBI was developed using back-translation for verification (Kitamura \& Suzuki, 1993). The validity of PBI was confirmed by a high consistence among the PBI dimensions of two parents recorded independently by the student, and his/her father and mother. Although a four-factor structure (Care, Indifference, Overprotection, and Autonomy) of the PBI is supported to fit Japanese samples, the factors of care and indifference are regarded as the two poles on one axis, and the factors of overprotection and autonomy as the poles forming the other 
axis (Uji, Tanaka, Shono, \& Kitamura, 2006). Therefore, in the present study, the original two-factor structure was used.

\section{Statistical Analysis}

We used $t$-test and MANOVA analyses to compare means between men and women among all the variables. We then calculated the descriptive statistics and correlations of all variables. We performed regression analysis to examine the extent to which adult attachment is predicted by perceived parenting and family functioning. The TAS was regressed as the criterion variable on the explanatory variables of four PBI and two FACES-III subscale scores, which were simultaneously forced to enter the formulation. We used SPSS 14.0 (SPSS Inc, 2005) to conduct all analyses. Finally, we designed a structural equation model (SEM) to examine the relationship between the variables of adult attachment, perceived parenting, and family functioning, based on the results of above analyses (Fig. 1). We used Amos 6.0 (Arbuckle \& Wothke, 2005) to perform this path analysis. The fit of the model with the present data was evaluated by the indices of goodness of fit, such as the Root Mean Squared Error of Approximation (RMSEA), the Goodness of Fit Index (GFI), and the Adjusted Goodness of Fit Index (AGFI). RMSEA $\leq .08$, GFI $\geq .90$, and AGFI $\geq .85$ indicate an acceptable fit; RMSEA $\leq .05$, GFI $\geq .95$, and AGFI $\geq .90$ indicate a good fit (Schermelleh-Engel, Moosbrugger, \& Müller, 2003).

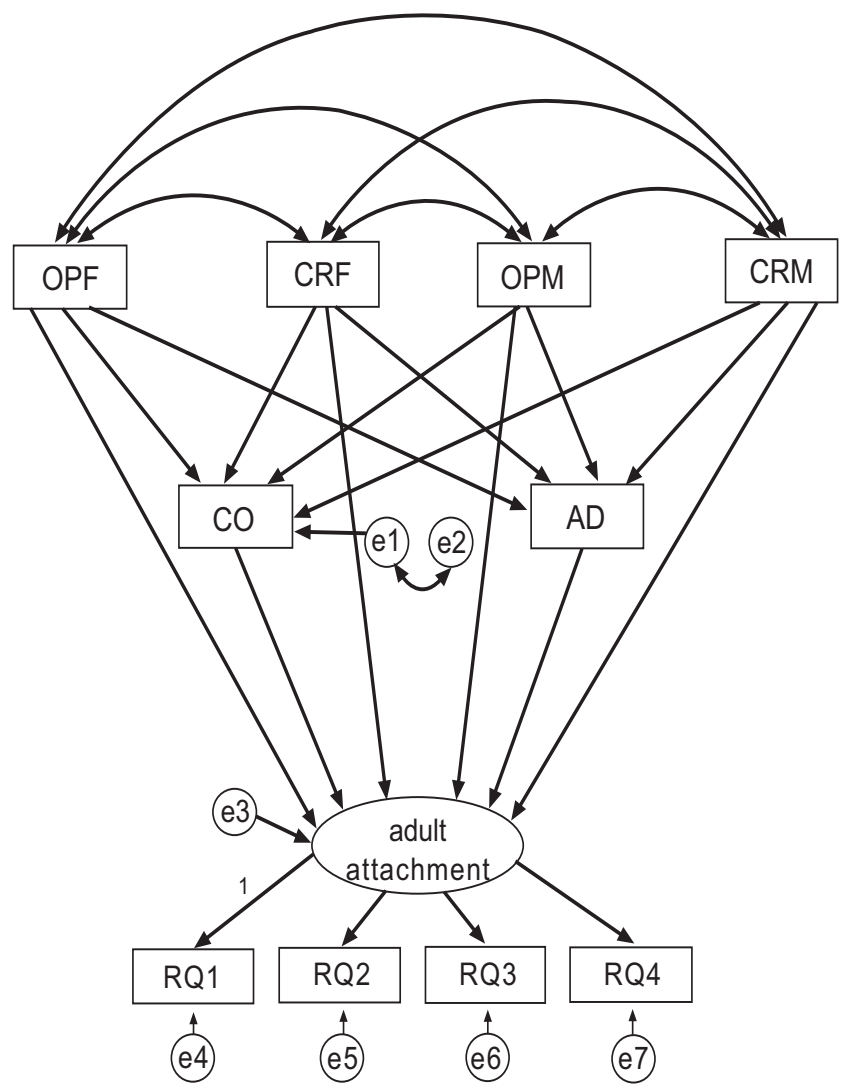

Fig (1). The hypothesized path model for parental rearing, family functioning, and adult attachment. Note: $\mathrm{OPF}=$ overprotection of father; $\mathrm{CRF}=$ care of father; $\mathrm{OPM}=$ overprotection of mother; $\mathrm{CRM}=$ care of mother; $\mathrm{CO}=$ cohesion of family; $\mathrm{AD}=$ adaptability of family.

\section{RESULTS}

\section{Confirmatory factor analyses of $\mathrm{RQ}$}

In order to confirm the single-factor structure originally proposed by Matsuoka et al. (2006), we performed confirmatory factor analysis of RQ using AMOS 6.0. The singlefactor structure of RQ was supported by GFI $=.995$, AGFI $=$ .973 , RMSEA $=.073$, indicating a good fit. The Cronbach alpha coefficients of the four items are .54 .

\section{Descriptive and bivariate statistics}

Although $t$-test results demonstrated no gender difference in TAS $(t=-1.824, p=.07)$, a significant gender difference between the four sub-styles was obtained with MANOVA $(F(1,3848)=19.586, p<.000)$. Moreover, there were significant gender differences in paternal Care and Overprotection $(F(1,3948)=50.294, p<.000)$, maternal Care and Overprotection $(F(1,3848)=35.290, p<.000)$, and Adaptability and Cohesion $(F(1,3848)=33.349, p<.000)$. Therefore, the following analyses were conducted separately for male and female students.

The means, standard deviations, and the correlation coefficients among all the variables for men and women are shown in Table 1. The TAS score was mildly but significantly correlated with subscales of PBI and FACES-III in both genders: positively for Adaptability and Cohesion of family as well as Care of father and mother, and negatively for Overprotection of father and mother. Both Adaptability and Cohesion of family were moderately associated with the PBI scores: positively for Care and negatively for Overprotection.

\section{Multiple Regression Analysis}

In order to examine whether adult attachment can be predicted by perceived parenting and current family functioning, we ran a regression analysis. Four PBI and two FACESIII scores were entered simultaneously into the formulation (Table 2).

Regression models for men and women were both significant $(F(6,1134)=12.239$ and $F(6,2702)=29.087$, respectively, $p<.001)$. Examination of the beta weights for predictors showed that (1) Adaptability and Cohesion of family had no significant contribution to the TASs in the models of both men and women; (2) the TASs in both men and women, and especially in women, were significantly predicted by paternal Care, whereas the TAS in just the women's model was significantly predicted by maternal Care; (3) paternal Overprotection failed to contribute to the TASs, while low maternal Overprotection significantly predicted the TAS in men and, to lesser degree, in women.

\section{Analysis of SEM}

In order to further examine the relationship among perceived parenting, family functioning, and adult attachment, we designed a hypothesized model of SEM (Fig. 1) based on the logic of time and the results of the above analyses. We then ran this original model on male and female samples separately and refined by deleting insignificant paths $(p>$ .05 ). The final models for men (Fig. 2) and women (Fig. 3) were obtained and all the path coefficients were significant $(p<.001)$. Indices of goodness of fit were RMSEA $=.031$, 
Table 1. Pearson Correlations, Means ( SDs) of All the Variables for Men and Women

\begin{tabular}{|c|c|c|c|c|c|c|c|c|c|}
\hline & $\mathbf{1}$ & $\mathbf{2}$ & $\mathbf{3}$ & $\mathbf{4}$ & $\mathbf{5}$ & $\mathbf{6}$ & $\mathbf{7}$ & Men's M(SD) & Women's M(SD) \\
\hline \hline $1 \mathrm{CRF}$ & & -.354 & .408 & -.215 & .569 & .411 & .202 & $23.4(7.4)$ & $24.9(7.3)$ \\
\hline $2 \mathrm{OPF}$ & -.441 & & -.251 & .556 & -.226 & -.324 & -.135 & $10.9(6.3)$ & $11.3(6.4)$ \\
\hline $3 \mathrm{CRM}$ & .487 & -.316 & & -.446 & .476 & .332 & .196 & $28.2(5.8)$ & $29.5(6.0)$ \\
\hline $4 \mathrm{OPM}$ & -.303 & .536 & -.498 & & -.242 & -.291 & -.148 & $11.5(7.1)$ & $11.6(7.2)$ \\
\hline $5 \mathrm{CO}$ & .561 & -.246 & .485 & -.274 & & .591 & .162 & $21.8(8.6)$ & $23.6(9.3)$ \\
\hline $6 \mathrm{AD}$ & .401 & -.301 & .329 & -.271 & .575 & & .123 & $20.2(5.9)$ & $21.2(6.5)$ \\
\hline $7 \mathrm{TAS}$ & .183 & -.157 & .177 & -.202 & .158 & .113 & & $-5.4(4.6)$ & $-5.1(4.5)$ \\
\hline
\end{tabular}

Note. $N=1,141$ for man and 2,709 for woman. All the correlations are significant at $p<.001$. The correlations for woman are above and those for man are under the diagonal. CRF $=$ care of father; $\mathrm{OPF}=$ overprotection of father; $\mathrm{CRM}=$ care of mother; $\mathrm{OPM}=$ overprotection of mother; $\mathrm{CO}=\mathrm{cohesion}$ of family; $\mathrm{AD}=\mathrm{adaptability}$ of family; $\mathrm{TAS}=$ total adult attachment score.

$\mathrm{GFI}=.990, \mathrm{AGFI}=.980$ for men and RMSEA $=.038, \mathrm{GFI}$ $=.991, \mathrm{AGFI}=.980$ for women, indicating that the two final models have a good fit with the present data.

Table 2. Regression Analysis Predicting Adult Attachment with the PBI and FACES-III

\begin{tabular}{|c|c|c|c|c|c|c|c|c|}
\hline \multirow{2}{*}{ Variables } & \multicolumn{4}{|c|}{ Men } & \multicolumn{4}{|c|}{ Women } \\
\hline & $\mathbf{R}^{2}$ & $\Delta \mathbf{R}^{2}$ & $\beta$ & $\mathbf{P}$ & $\mathbf{R}^{2}$ & $\Delta \mathbf{R}^{2}$ & $\beta$ & $\mathbf{P}$ \\
\hline & \multirow[t]{7}{*}{.061} & \multirow[t]{7}{*}{$.061^{* * *}$} & & & \multirow[t]{7}{*}{.061} & \multirow[t]{7}{*}{$.061^{* * *}$} & & \\
\hline $\mathrm{CO}$ & & & .053 & 191 & & & .023 & .384 \\
\hline $\mathrm{AD}$ & & & -.008 & .815 & & & -.001 & .967 \\
\hline $\mathrm{CRF}$ & & & $.087^{*}$ & .025 & & & $.125^{* * *}$ & .000 \\
\hline OPF & & & -.026 & .474 & & & -.031 & .190 \\
\hline CRM & & & .039 & .307 & & & $.102^{* * * *}$ & .000 \\
\hline OPM & & & $-.130^{*}$ & .001 & & & $-.051^{*}$ & .041 \\
\hline
\end{tabular}

Note: ${ }^{*}$ are at $p<.05,{ }^{* *}$ are at $p<.01,{ }^{* * *}$ are at $p<.001$.

$\mathrm{CRF}=$ care of father; $\mathrm{OPF}=$ overprotection of father; $\mathrm{CRM}=$ care of mother; $\mathrm{OPM}=$ overprotection of mother; $\mathrm{CO}=$ cohesion of family; $\mathrm{AD}=$ adaptability of family.

The SEM analysis demonstrated the same results using the regression analysis: Adaptability and Cohesion of current family functioning did not predict adult attachment in either sample; adult attachment in men was predicted by low maternal Overprotection and high paternal Care; adult attachment in women was predicted by low maternal Overprotection and high Care by both parents. Furthermore, the relationship between perceived early parenting and current family functioning was clarified: Cohesion in both men and women was predicted only by high Care of both parents; Adaptability in both men and women was predicted by low paternal Overprotection and high Care of both parents. Low maternal Overprotection had only a weak influence on Adaptability in female samples.

\section{DISCUSSION}

The main purpose of the present study was to examine how adult attachment was influenced by perceived rearing and current family functioning. In zero-order correlations, results of the present study are consistent with those of prior

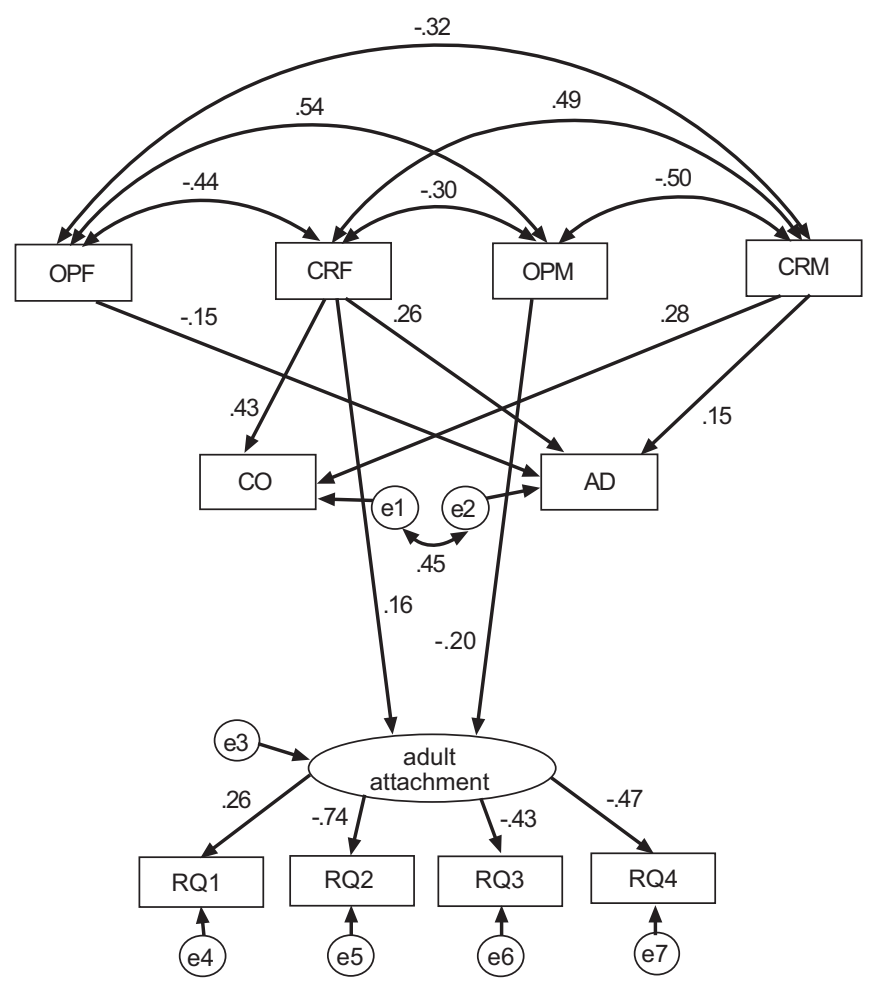

Fig. (2). Men's path model for parental rearing, family functioning, and adult attachment (all the path coefficients are $p<.001$ ).

research, specifically that adult attachment is associated with perceived rearing and family functioning among both men and women (Hazan \& Shaver, 1987; Mikulincer \& Florian, 1998, 1999). However, our regression analysis for current family functioning yielded different results compared with prior studies (Mikulincer \& Florian, 1999). The first hypothesis that adult attachment style would be predicted by perceived early parenting and current family functioning when these two factors are simultaneously taken into account was partially supported. Examination of the beta weights for the predictor variables reveals that adaptability and cohesion fail to significantly predict adult attachment in both male and female samples. The second hypothesis that current family functioning would be predicted by perceived early parenting was supported by the results of SEM as expected. 


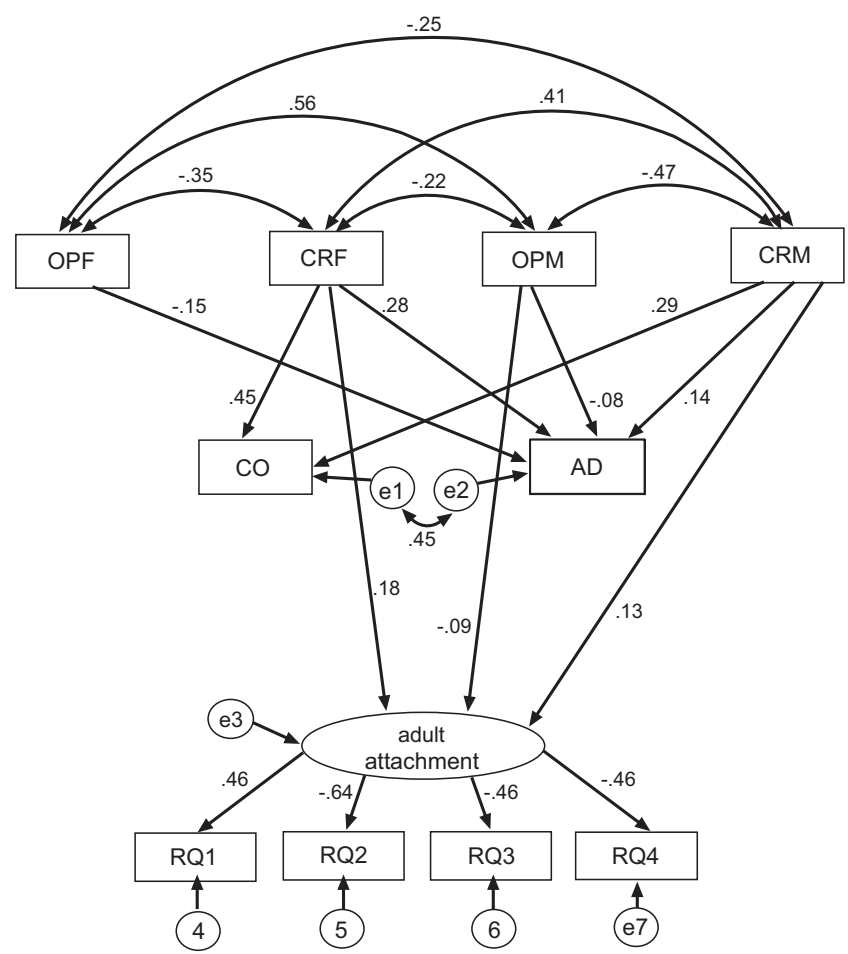

Fig. (3). Women's path model for parental rearing, family functioning, and adult attachment (All the path coefficients are at $\mathrm{p}<.001$ ).

The present findings suggest that while current family functioning is univariately correlated with adult attachment, this association is highly dependent on the correlation between perceived rearing and family functioning. Once family functioning and perceived rearing are entered together in a multivariate regression model, the role of family functioning is no longer significant. Although recent studies have demonstrated that negative life experiences, especially ones in the family environment, often cause changes in attachment styles from infancy through early adulthood (Hamilton, 2000; Waters, Merrick, Treboux, Crowell, \& Albersheim, 2000; Waters, Weinfield, \& Hamilton, 2000), around 70-80 percent of people experience no significant changes in attachment styles over time (Baldwin \& Fehr, 1995; Kirkpatrick \& Hazan, 1994). Furthermore, in a longitudinal study using a sample of young adults, Scharfe and Bartholomew (1994) confirmed that adult attachment representations as assessed by self-report show high stability. Therefore, individuals' current levels of attachment may be hardly influenced by current family functioning. Further longitudinal studies on this inference are needed.

Parental care is characterized by affection, emotional warmth, and closeness. In contrast, parental overprotection is marked by intrusiveness, demand for obedience, and overcontrol. Therefore, according to attachment theories, high care and low overprotection are necessary for an individual's secure attachment, while low care and high overprotection are considered to be the source of distorted bonding. This view is verified by our results showing that adult attachment is associated positively with paternal and maternal care and negatively with paternal and maternal overprotection. It is in line with prior studies which indicate that different parenting styles of both parents have different influences on the outcome of the offspring, such as delinquency, eating disorders, and personality traits (Biggam \& Power, 1998; Philip Tata, 2001; Reti et al., 2002). However, the results of regression analysis in this study show that not all care and overprotection by parents directly predict the adult attachment of their offspring. High paternal care and low maternal overprotection directly predict secure adult attachment of male and female offspring; high maternal care directly predicts adult attachment only among female offspring; paternal overprotection has no direct and significant effect on adult attachment of either samples. It is noteworthy that although attachment theories emphasize the role of a child's mother due to her role of main caregiver, the present findings have provided evidence that fathers also play an indispensable part during the development of attachment.

SEM is a more powerful alternative to multiple regression and path analysis. Advantages of SEM compared to multiple regression analysis include the possibility of examining the goodness of fit of a model and the ability to improve the causal model according to both scientific and statistical views (Kano, 2002). The results of SEM in this study show the same conclusion as that seen in multiple regression analysis as regards the relationship between adult attachment and perceived rearing as well as current family functioning. Further, the SEM model suggests that although paternal overprotection in both samples and maternal care in the male sample fail to directly influence adult attachment of offspring, these variables may indirectly predict adult attachment through covariance with other PBI variables.

Another purpose of the present study was to try to verify whether current family functioning can be predicted by perceived early parenting. As expected, this hypothesis was confirmed by the results of SEM analysis. Moreover, our findings indicate that perceived rearing by both parents has more influence on adaptability than cohesion. Only maternal overprotection fails to directly predict family adaptability in the male sample, while both paternal and maternal overprotection fail to have a direct influence on family cohesion in both samples of men and women.

Limitations of the present study should also be acknowledged. Due to the extent of our investigation, it was designed to be cross-sectional. Therefore, caution should be exercised in making a conclusion because the presence of a crosssectional design is one of the main reasons for failing to explore causal relationships. However, PBI assessed the attitudes and behaviors of parents that were perceived by offspring up to sixteen years of age but recalled in the present time, while FACES-III and RQ evaluated individuals' current state. Thus, taking into account these time sequences, testing the causal relationships between perceived rearing, current family functioning, and adult attachment should not be a problem. In addition, because it was impractical to supervise the processes of distribution in 110 universities, the exact response rate to the questionnaire was unknown. This made it impossible to compare the demographic information of participants and non-participants and to some extent hampers the generalizability of the present findings.

In short, the present study highlights the fact that paternal parenting is at least as important as maternal parenting in terms of influence on adult attachment of offspring. Parenting also has an important influence on the family functioning - adaptability and cohesion. 


\section{REFERENCES}

Ainsworth, M. D. S., Blehar, M. C., Waters, E., \& Wall, S. (Eds.). (1978). Patterns of attachment: A psychological study of the strange situation. Hillsdale, NJ: Erlbaum.

Arbuckle, J. L., \& Wothke, W. (Eds.). (2005). Amos 6.0 User's Guide. Chicago, IL: SmallWater.

Arendell, T. (Eds.). (1997). Contemporary parenting: Challenges and issues. Thousand Oaks, CA: Sage.

Aunola, K., \& Nurmi, J. E. (2005). The role of parenting styles in children's problem behavior. Child Development, 76(6), 1144-1159.

Baldwin, M. W., \& Fehr, B. (1995). On the instability of attachment style ratings. Personal Relationships, 2(3), 247-261.

Bartholomew, K., \& Horowitz, L. M. (1991). Attachment styles among young adults: A test of a four-category model. Journal of Personality and Social Psychology, 61(2), 226-244.

Baumrind, D. (1996). The discipline controversy revisited. Family Relations, 45, 405-414.

Biggam, F. H., \& Power, K. G. (1998). The quality of perceived parenting experienced by a group of Scottish incarcerated young offenders and its relation to psychological distress. Journal of Adolescence, 21(2), 161-176.

Bowlby, J. (Eds.). (1969). Attachment and loss: Vol. 1. Attachment. New York: Hogarth Press.

Bowlby, J. (Eds.). (1973). Attachment and loss: Vol. 2. Separation. New York: Basic Books.

Bowlby, J. (Eds.). (1980). Attachment and loss. Vol. 3 Loss, sadness and depression. New York: Basic Books.

Crittenden, P. M., \& Ainsworth, M. D. S. (1989). Child maltreatment and attachment theory. In D. Cicchetti \& V. Carlson (Eds.), Clinical maltreatment: Theory and research on the causes and consequences of child abuse and neglect (pp. 432-463). Cambridge, England: Cambridge University Press.

Damon, W. (Eds.). (1988). The moral child: Nurturing children's natural moral growth. New York: Free Press.

Egeland, B., \& Farber, E. A. (1984). Infant-mother attachment: Factors related to its development and changes over time. Child Development, 55(3), 753-771.

Griffin, D. W., \& Bartholomew, K. (1994). The metaphysics of measurement: the case of adult attachment. In K. Bartholomew \& D. Perlman (Eds.), Advances in Personality Relationship, Vol. 5 Attachmentprocesses in Adulthhood (pp. 17-52). London: Jessica Kingsley.

Grotevant, H. D., \& Carlson, C. I. (Eds.). (1989). Family Assessment: A guide to Methods and Measures. New York: Guilford Press.

Hamilton, C. E. (2000). Continuity and discontinuity of attachment from infancy through adolescence. Child Development, 71(3), 690-694.

Hasui, C., Kishida, Y., \& Kitamura, T. (2004). Factor structure of the FACES-III in Japanese university students. Family Process, 43(1), 133-140.

Hazan, C., \& Shaver, P. R. (1987). Romantic love conceptualized as an attachment process. Journal of Personality and Social Psychology, 52(3), 511-524.

Hazan, C., \& Shaver, P. R. (1990). Love and work: An attachment theoretical perspective. Journal of Personality and Social Psychology, 59(2), 270-280.

Hazan, C., \& Shaver, P. R. (1994). Attachment as an organizational framework for research on close relationships. Psychological Inquiry, $5(1), 1-22$.

Kano, Y. (2002). Does structural equation modeling outperform traditional factor analysis, analysis of variance and path analysis? Japanese Journal of Behaviormetrics, 29(2), 138-159.

Kirkpatrick, L. A., \& Hazan, C. (1994). Attachment styles and close relationships: A four-year prospective study. Personal Relationships, $1(2), 123-142$.
Kitamura, T., \& Suzuki, T. (1993). A validation study of the Parental Bonding Instrument in a Japanese population. Japanese Journal of Psychiatry and Neurology, 47(1), 29-36.

Kochanska, G., Kuczynski, L., \& Radke-Yarrow, M. (1989). Correspondence between mothers' self-reported and observed child-rearing practices. Child Development, 60(1), 56-63.

Matsuoka, N., Uji, M., Hiramura, H., Chen, Z., Shikai, N., Kishida, Y., et al. (2006). Adolescents' attachment style and early experiences: A gender difference. Health Archives of Women's Mental Health, 9(1), 23-29.

McFarlane, A. H., Bellissimo, A., \& Norman, G. R. (1995). Family structure, family functioning and adolescent well-being: The transcendent influence of parental style. Journal of Child Psychology and Psychiatry, 36(5), 847-864.

Mikulincer, M., \& Florian, V. (1998). The relationship between adult attachment styles and emotional and cognitive reactions to stressful events. In J. A. Simpson \& W. S. Rholes (Eds.), Attachment theory and close relationships (pp. 143-165). New York: Guilford Publications.

Mikulincer, M., \& Florian, V. (1999). The association between parental reports of attachment style and family dynamics, and offspring's reports of adult attachment style. Family Process, 38(2), 243-257.

Mupinga, E. E., Garrison, M. E. B., \& Pierce, S. H. (2002). An exploratory study of the relationships between family functioning and parenting styles: The perceptions of mothers of young grade school children. Family and Consumer Sciences Research Journal, 31(1), 112-129.

Olson, D. H. (1991). Three-dimensional (3-D) Circumplex Model and revised scoring of FACES III. Family Process, 30(1), 74-79.

Olson, D. H., \& DeFrain, J. (Eds.). (2000). Marriage and the family: Diversity and strengths. Mountain View, CA: Lawrence Erlbaum.

Olson, D. H., Portner, J., \& Lavee, Y. (Eds.). (1985). FACES-III (Family Adaptation and Cohesion Scales). St. Paul, MN: Family Science, University of Minnesota.

Parker, G., Tupling, H., \& Brown, L. B. (1979). A Parental Bonding Instrument. British Journal of Medical Psychology, 52, 1-10.

Philip Tata, J. F. J. C. (2001). An investigation into the influence of gender and parenting styles on excessive exercise and disordered eating. European Eating Disorders Review, 9(3), 194-206.

Reti, I. M., Samuels, J. F., Eaton, W. W., Bienvenu Iii, O. J., Costa Jr, P. T., $\&$ Nestadt, G. (2002). Influences of parenting on normal personality traits. Psychiatry Research, 111(1), 55-64.

Scharfe, E., \& Bartholomew, K. I. M. (1994). Reliability and stability of adult attachment patterns. Personal Relationships, 1(1), 23-43.

Schermelleh-Engel, K., Moosbrugger, H., \& Müller, H. (2003). Evaluating the fit of structural equation models: Test of significance and descriptive goodness-of-fit measures. Methods of Psychological Research Online, 8, 23-74.

Smith, T. E. (1988). Parental control techniques: Relative frequencies and relationships with situational factors. Journal of Family Issues, 9 , 155-176.

SPSS Inc. (Eds.). (2005). SPSS 14.0 for Windows. Chicago, IL: SPSS, Inc.

Uji, M., Tanaka, N., Shono, M., \& Kitamura, T. (2006). Factorial structure of the parental bonding instrument (PBI) in Japan: a study of cultural, developmental, and gender influences. Child Psychiatry and Human Development, 37(2), 115-132.

Waters, E., Merrick, S., Treboux, D., Crowell, J., \& Albersheim, L. (2000). Attachment security in infancy and early adulthood: A twenty-year longitudinal study. Child Development, 71(3), 684-689.

Waters, E., Weinfield, N. S., \& Hamilton, C. E. (2000). The Stability of Attachment Security from Infancy to Adolescence and Early Adulthood: General Discussion. Child Development, 71(3), 703706. 